\title{
The Impact of a Training Program Based on Betts Autonomous Learner Model on Developing Creative Leadership and Problem-Solving Skills of Gifted Students in Jordan
}

\author{
Saida Kuftan Aladwan \\ Department of Special Education, Al-Balqa Applied University, Jordan \\ Received November 8, 2020; Revised December 16, 2020; Accepted January 20, 2021
}

\begin{abstract}
Cite This Paper in the following Citation Styles
(a): [1] Saida Kuftan Aladwan, "The Impact of a Training Program Based on Betts Autonomous Learner Model on Developing Creative Leadership and Problem-Solving Skills of Gifted Students in Jordan," Universal Journal of Educational Research, Vol. 9, No. 1, pp. 241 - 252, 2021. DOI: 10.13189/ujer.2021.090126.
\end{abstract}

(b): Saida Kuftan Aladwan (2021). The Impact of a Training Program Based on Betts Autonomous Learner Model on Developing Creative Leadership and Problem-Solving Skills of Gifted Students in Jordan. Universal Journal of Educational Research, 9(1), 241 - 252. DOI: 10.13189/ujer.2021.090126.

Copyright $\bigcirc 2021$ by authors, all rights reserved. Authors agree that this article remains permanently open access under the terms of the Creative Commons Attribution License 4.0 International License

\begin{abstract}
Aim: The present study investigated the impact of a training program based on Autonomous learner model of Betts on developing creative leadership skills of gifted students in Jordan. Method: The study adopted the quasi-experimental approach. A sample of 60 Jordanian gifted students were recruited from the "Talent and Creativity Program" launched by International Pioneers Academy in Amman. The study sample was divided randomly into a control group $(\mathrm{n}=30)$ and an experimental group $(n=30)$. The researcher designed a creative leadership scale that investigated 11 domains, they were: Vision, planning, social communication, motivation, team building, public relations, management, communication, conflict resolving, decision making, and problem solving. The designed training program included activities that focused on learners' autonomy through a set of activities that allow the students to use their metacognitive and behavioral abilities. Results: The results of the study showed that there were significant statistical differences in the post-assessment of the creative leadership scale between the control group and the experimental group at a significance level $(\alpha \leq 0.05)$. Conclusion: The study concluded the effectiveness of the training program based on Betts learner autonomy model on developing the creative leadership and problem solving skills among Jordanian gifted students. The study recommended
\end{abstract}

providing a comprehensive educational and training package to activate the autonomous learning programs designed for developing the creative leadership and problem solving skills among gifted students.

Keywords Gifted Students, Training Program, Betts Learner Autonomy Model, Jordan, Quasi-Experimental

\section{Introduction}

Contemporary trends and modern educational initiatives have increased demanding the necessity of providing social contexts that support the integrated growth of various aspects of personality [1], and that learning and training processes are not limited to academic achievement goals alone, as interactive contexts play an important role in achieving this; Because it represents a real theater in which the child's experiences are translated on the ground in the form of practical behaviors that can be observed and modified, through which the skills and rules of dealing with others are developed, and the values of respect, cooperation, self-development, and training in various life skills are promoted [2]. Despite the inevitability of human growth 
with advancing age, it is not at the same level for all learners, as the level of growth in addition to readiness is related to the amount of training and care that the learner receives [3].

The results of George Betts' research efforts have added a qualitative importance in the fields of human learning and its growth, as it formed a new framework for understanding the growth and learning of the individual, assuming that there is a close interactive relationship between the cultural contexts in which the individual lives with their tools and their historical development on the one hand [3]. and between the nature and manner of growth and learning on the other hand, assuming that learning and growth by their nature are dynamic, cultural, interactive processes, and that they are the product of the interactions of learners, who are driven by their nature to create interactive contexts through which they develop their ideas and knowledge, which increases the outcome of experiences affecting their later learning and growth [4].

George Betts set out in his assumptions that the learner is an individual in a society with his own personal characteristics, his personality unique to his peers inside and outside the educational context[3], and an attempt to obliterate the characteristics of this personality and deny the learner's self, is in itself a palm of the abilities and energies inherent in the same learner, which can be used in one way or another to support and activate its learning processes [5].

It is obvious that modern education looks at the learner as a partner in the educational process and not just a passive recipient on whom educational activities are imposed by the teacher or by the curriculum developers [6]. The fact that the learners are partners in the educational process means that they influence the setting of goals and the choice of content and bear a large part of the responsibility for their learning. On the part of the teacher, he/she plays the role of a facilitator that provides the appropriate conditions for learning in cooperation with the learner itself and is not alone, as is the case in traditional practices, imposing their absolute authority and disguising the learner needs and requirements [7].

There is a real need for gifted students who can become community leaders to be given the opportunity to develop leadership skills and creative thinking [8]. Unique ideas emerge from individuals who have already developed a broad base of knowledge, and from those eager to develop approaches towards creative production. Great leaders are essentially good thinkers [7]. Perhaps leadership development programs for gifted students can include activities such as reading, discussion, group projects, working with supervisors, and self-assessment of leadership skills and values associated with experiences from reality [9]. Real-world experiences of leadership behavior provide the gifted with opportunities to experiment with the leadership behaviors offered by the leadership program, and it also helps them develop a range of leadership skills [10].

Curricula should assist students gifted in leadership to develop knowledge of values, ethics, and philosophical systems; From a general perspective, the importance of leadership in general is due to many reasons, including: The success or failure of any group or institution depends to a large extent on the characteristics of leadership in it [11]. Leadership is a major criterion for judging the success or failure of that group or institution, and leadership affects fundamentally in the behavior of the followers and their attitudes towards the group and their unification with it, and they play an effective role in determining the ability of the majority to act and explode the energies, and they succeed in converting them into positive actions or activities with their creative ideas aimed at identifying or improving the legacy, and inventing the latest from the systems [12], The increasing need in all societies, and developing societies in particular, for leaders who are able to organize and develop, and are able to assume responsibility and dedication to the practice of the requirements of their leadership roles gives leadership great importance [8]. The researchers have paid attention to leaders because they are a wealth that society possesses that must be invested and studying all the influences that preserve it, in addition to the various dimensions and aspects related to it, to identify its distinctive characteristics, to explore its basic determinants, and to assist in the efficient employment of information that results from these scientific efforts, in addition to benefiting from it in situations of discovering leadership elements, and developing their skills [13].

Karagianni indicated that the gifted students in leadership possess the leadership personality that helps them in communicating with others and making the right decisions and the tendency to work in groups, as they are characterized by self-confidence and love of competition. The gifted student by nature has qualities that he/she can benefit from practice leadership [14], and those qualities mentioned by Al-Tureif et al [15], are namely: participation in the decision-making process, which management scholars advise all leaders in the modern era to adhere to. Also, the leading person tends to participate in reform and correction. The trait of empathy with others is one of the qualities possessed by the leadership personality as it appreciates the needs of colleagues and their circumstances, which helps him/her to build real relationships that make his/her followers love him/her and move with him/her towards common goals with their desire, and this gifted is also characterized by creativity, which gives him/her the ability to find unprecedented solutions in the situations that he/she presides.

A group of studies focused on developing leadership skills that affect the education of gifted students, including the Smyth and Ross [16] study, which aimed to develop leadership skills among gifted students in the classroom 
by interacting with small groups of students. The study was conducted on a sample consisting of (25) gifted students in the fourth to sixth grades of elementary school. The sample was divided into three groups, in the following manner: The first group includes (16) gifted students divided into five subgroups, while the second group includes (12) students distributed into six subgroups, where three groups of them include gifted students and three other groups include ordinary students. The third group included (22) students, who were divided into three groups. Each group includes one gifted student, and the rest are normal, and the number of group members ranges from (4-5) students. An educational program, represented by information about leadership, was introduced to the students. The study concluded that leadership behavior has developed among gifted students after the experimental procedure, and it was also found that leadership appears more clearly among gifted students, if the small group in which they work includes non-gifted students.

The study of Al-Mannai (2010) aimed to identify the effect of the leadership skills program on leadership skills and creativity among a sample of (59) students who excelled in secondary school in the Kingdom of Bahrain. The study sample was divided as following: (The experimental group (31 students) and the control group (28 students). In this study, the Raven Sequential Matrix Test, the Impact Test to measure the creative ability (fluency and originality) of Abd al-Salam Abd al-Ghaffar, quoting from Torrance, and the Creative Traits Scale of Zain Al-Abidine Darwish were used in this study. The study found the following results: There are positive differences in leadership skills between the experimental and control groups in favor of the experimental group, there are positive differences in the creativity capacity between the experimental and control groups in favor of the experimental group, there are no differences in both leadership skills and creative ability between males and females [17].

Based on the foregoing and believing in the importance of developing and improving creative leadership skills among students as they are the backbone of advancement in societies, it was chosen to study the impact of a training program based on Autonomous learner model of Betts on developing creative leadership skills of gifted students in Jordan.

\section{Purpose of the Study}

The current study seeks to investigate the impact of a training program based on Autonomous learner model of Betts on developing creative leadership skills of gifted students in Jordan

\section{Significance of the Study}

Many of the talents and aspects of superior behavior of the individual can be developed from childhood, especially since the role of psychology is no longer focused on modifying and correcting behavior, but rather it goes beyond that and plays a greater role to include contributing to the development of positive behavior in the individual, which makes us assure that the aspects of superior behavior in the field of leadership can be developed since childhood (Al-Mannai, 2010). Leadership behavior and the presence of a good leader is very important, but a large part of the nation's backwardness in various fields is due to the lack of enough leaders in organizations and institutions.

The importance of the current study is as follows:

The lack of regional experimental studies for training programs targeting creative leadership skills. This study provides a systematic model of leadership that deals with the theoretical and practical aspects represented in training activities and practical workshops that develop creative leadership skills. This study also comes in response to the needs for the educational field in general, and the field of talent and creativity in particular, to provide a training program that develops creative leadership skills and improves them among gifted students in Jordan. In addition, this study provides an enrichment of psychological research and studies by providing a training program aimed at gifted students of sensitive age.

In the end, the results of the current study may serve to guide officials and decision-makers to the importance of developing creative leadership skills for gifted students, which would contribute to the development of the local community to which this student group belongs.

\section{Research Definitions}

Autonomous Learner: An autonomous learner is "one who solves problems or develops new ideas through a combination of divergent and convergent thinking functions with minimal external guidance in selected areas endeavor" [4].

Autonomous Learner Model (ALM): "is a learning model that was developed specifically to meet the diversified cognitive, emotional and social needs of learners. While it was originally developed for gifted learners, it has proven to be effective in developing life-long learning for all students" [5]

Gifted Students: They are students who are characterized by the ability to perform distinctively in the field of creative, artistic and leadership abilities or in specific academic fields. These students who possess extraordinary abilities and capabilities appear in their high and distinguished performance, which are identified by qualified and experienced specialized experts [18].

Leadership: Leadership is a process of influencing the behavior of people at work towards the achievement of specified goals. There are several definitions of the term leadership, such as leadership is the activity of influencing 
people to strive willingly for group objectives. Leadership is the initiation of acts which result in a consistent pattern of group interaction directed towards the solution of a mutual problem [19].

Creative Leadership: It is the intended ability to engage the individual's imagination, to identify and direct group members towards a noble goal in the direction of what is new for the members of that group. As a result of creating creativity, a creative leader has a profound positive effect on the members of the group or the environment in which they collaborate [20]

\section{Theoretical Framework}

\section{Autonomous Learner Model}

The autonomous learner model was created by George Betts and Jolene Kircher in the 1970s and 1980s. It was created to target both achieving and non-achieving gifted students to become independent creative and responsible learners; this means that these students will solve problems and investigate ideas and topics with minimal external guidance. there are five dimensions that when followed lead students to become autonomous lifelong learners. the first dimension is called orientation; this is when their parents and teachers learn all about the model, its goals and the program, this is also when students learn about what is intelligence, what is creativity and what does it mean to be gifted. The second dimension is called individual development [21]; it provides learners with the opportunity to develop the cognitive, emotional, social, and physical skills, in addition to developing concepts and attitudes necessary for lifelong learning. Learners gain the skills needed to take an active role in their learning process through individual development. This dimension includes inter and intra personal development learning and organizational skills. Use of technology and information about college and career involvement during the enrichment dimension, which is the third dimension, is when students begin to explore content that is outside of the school curriculum. Learners are able to discover content outside of what the school provides, which fits their learning needs, they start with explorations and they complete investigations and then cultural activities can allow for participation in community events and service activities can encourage learners to help make the world a better place [5]. If students are to become learners, then they must have the opportunity for independent individual and group learning, which means having a structure that allows and promotes the development of new knowledge for the individuals is the purpose of the seminar dimension, this dimension aims to give learners a chance to work on a research topic independently and then present a seminar to others based on their research. The fifth and final dimension of the autonomous learner model is called the in-depth study dimension. This is when learners will determine what they will learn, how they will learn it, how they will present it, and also what facilitation will be necessary for their assistance. They also get to decide how their learning process will be assessed. This is the completed autonomous learner model by George Betts, it includes all five dimensions. I think it's important to note that Betts made two important distinctions in his writing; he distinguished a student from a learner, he said that students relied on teachers for knowledge while learners pursue passions by developing skills and seeking knowledge, he also made the distinction between a teacher who is one who dispenses knowledge versus a facilitator who is one that supports and encourages the learning process [4].

\section{Methodology}

\section{Research Design}

The present study adopted the quasi-experimental research approach.

\section{Research Population}

The population in this study comprised of all gifted students enrolled in the "Talent and Creativity Program" launched by International Pioneers Academy in Amman. This program included 283 gifted students from different public and private schools in Amman city, Jordan. The Talent and Creativity Program was introduced as an independent program in response to the increasing needs of the gifted student group, as well as to provide the best services for them, as the program provides care for gifted students through their discovery, provision of special educational services and the development of the gifted students' abilities to achieve the development of talent and creativity in them to the maximum of their potential. It offers a set of their own training courses such as a gifted personality development course entitled (Who am I and what I want to be, a short story writing strategies course, a creative in mathematics course).

\section{Research Sample}

The study sample consisted of 60 students who were enrolled in the "Talent and Creativity Program" launched by International Pioneers Academy in Amman. The students in this program were aged 9 to 17 years. The study sample was distributed randomly into a control group $(n=30)$ who received traditional learning and an experimental group $(n=30)$ that enrolled in a training program based on Betts autonomous learner model.

The homogeneity of the two groups was examined using the domains of the creative leadership skills scale, which are: Vision, planning, social communication, motivation, team building, public relations, management, communication, conflict resolving, decision making, and 
problem solving. Means and standard deviation scores for each skill were calculated (Table 1). As noticed from the results shown in table 1 , there were no significant differences in the gifted students' mean scores in both groups, as the mean score of the experimental group was close to the mean score of the control group in all creative leadership skills, which means that the two groups are homogenous.

\section{Research Instruments}

The current study adopted a creative leadership skills scale that was administered pre and post of the designed training program based on Betts autonomous learner model. The scale consisted of 11 domains; they are: vision, motivation, social communication, problem solving, team building, communication, conflict resolving, planning, decision making, public relations, and management. A five-point Likert scale was adopted as following: Always (1), Often (2), Sometimes (3), Rarely (4), and Never (5).

\section{Validity and Reliability}

\section{Content Validity}

Content validity measures the opinion of specialists in the field that the scale measures through its items based on some criteria that the scale developer considers, such as its suitability and its representation of the goal to be measured. The scale was presented in its initial form to five jury members who are specialists in educational sciences and creativity. They were asked to determine the linguistic relevance of each statement of the scale, its relevance to the student and its relevance to leadership skills, as well as its relevance to creative skills.

Table 1. Homogeneity test of the control and experimental groups on the creative leadership skills scale

\begin{tabular}{|c|c|c|c|c|c|c|}
\hline \multirow[t]{2}{*}{ Creative leadership skills } & \multicolumn{2}{|c|}{$\begin{array}{c}\text { Experimental group } \\
(\mathrm{n}=30)\end{array}$} & \multicolumn{2}{|c|}{$\begin{array}{c}\text { Control group } \\
(\mathrm{n}=30)\end{array}$} & \multirow[t]{2}{*}{$\mathrm{t}$} & \multirow[t]{2}{*}{ sig } \\
\hline & M & SD & $\mathrm{M}$ & SD & & \\
\hline Vision & 29.667 & 3.435 & 29.300 & 4.549 & .352 & .726 \\
\hline Planning & 28.667 & 3.294 & 29.833 & 4.227 & 1.192 & .238 \\
\hline Social Communication & 30.400 & 2.268 & 30.000 & 3.523 & .495 & .623 \\
\hline Motivation & 29.933 & 3.362 & 29.667 & 4.559 & .258 & .797 \\
\hline Team building & 29.433 & 4.141 & 29.567 & 4.091 & .125 & .901 \\
\hline Public relations & 30.833 & 3.332 & 30.400 & 3.944 & .460 & .647 \\
\hline Management & 29.467 & 3.411 & 29.500 & 4.150 & .034 & .973 \\
\hline Communication & 29.567 & 3.559 & 29.800 & 3.989 & .242 & .810 \\
\hline Conflict resolving & 30.100 & 2.928 & 30.367 & 3.699 & .295 & .769 \\
\hline Decision making & 29.800 & 4.046 & 29.200 & 4.762 & .535 & .595 \\
\hline \multirow[t]{2}{*}{ Problem solving } & 30.367 & 4.386 & 30.500 & 3.763 & .138 & .891 \\
\hline & M: Mean & SD: Stand & ion & ance va & & \\
\hline
\end{tabular}


Table 2. Correlation coefficients between the creative leadership scale items and the total scale score and the domain score

\begin{tabular}{|c|c|c|c|c|c|c|c|c|}
\hline Item & $\begin{array}{c}\text { with } \\
\text { domain }\end{array}$ & With scale & Item & $\begin{array}{c}\text { with } \\
\text { domain }\end{array}$ & With scale & Item & $\begin{array}{c}\text { with } \\
\text { domain }\end{array}$ & With scale \\
\hline \multicolumn{3}{|c|}{ Vision skills } & \multicolumn{3}{|c|}{ Planning skills } & \multicolumn{3}{|c|}{ Social Communication skills } \\
\hline 1 & .844 & .672 & 8 & .817 & .702 & 15 & .866 & .739 \\
\hline 2 & .840 & .723 & 9 & .691 & .579 & 16 & .745 & .607 \\
\hline 3 & .704 & .465 & 10 & .690 & .497 & 17 & .798 & .822 \\
\hline 4 & .652 & .650 & 11 & .643 & .524 & 18 & .587 & .580 \\
\hline 5 & .674 & .511 & 12 & .629 & .575 & 19 & .641 & .524 \\
\hline 6 & .824 & .639 & 13 & .799 & .736 & 20 & .747 & .552 \\
\hline 7 & .661 & .683 & 14 & .572 & .477 & 21 & .613 & .533 \\
\hline \multicolumn{3}{|c|}{ Motivation skills } & \multicolumn{3}{|c|}{ Team building skills } & \multicolumn{3}{|c|}{ Public relations skills } \\
\hline 22 & .527 & .445 & 29 & .471 & .455 & 36 & .409 & .510 \\
\hline 23 & .461 & .517 & 30 & .731 & .757 & 37 & .808 & .591 \\
\hline 24 & .697 & .718 & 31 & .329 & .659 & 38 & .565 & .878 \\
\hline 25 & .605 & .676 & 32 & .206 & .478 & 39 & .801 & .745 \\
\hline 26 & .468 & .664 & 33 & .689 & .731 & 40 & .294 & .419 \\
\hline 27 & .579 & .709 & 34 & .434 & .552 & 41 & .395 & .510 \\
\hline 28 & .704 & .778 & 35 & .600 & .549 & 42 & .532 & .633 \\
\hline \multicolumn{3}{|c|}{ Management skills } & \multicolumn{3}{|c|}{ Communication skills } & \multicolumn{3}{|c|}{ Conflict resolving skills } \\
\hline 43 & .687 & .784 & 50 & .389 & .502 & 57 & .630 & .625 \\
\hline 44 & .428 & .125 & 51 & .338 & .474 & 58 & .566 & .741 \\
\hline 45 & .747 & .797 & 52 & .763 & .769 & 59 & .370 & .684 \\
\hline 46 & .674 & .753 & 53 & .620 & .714 & 60 & .298 & .529 \\
\hline 47 & .617 & .701 & 54 & .716 & .756 & 61 & .367 & .477 \\
\hline 48 & .723 & .729 & 55 & .778 & .806 & 62 & .404 & .709 \\
\hline 49 & .558 & .682 & 56 & .698 & .689 & 63 & .536 & .700 \\
\hline \multicolumn{3}{|c|}{ Decision making skills } & \multicolumn{3}{|c|}{ Problem solving skills } & & & \\
\hline 64 & .416 & .591 & 71 & .128 & .526 & & & \\
\hline 65 & .680 & .706 & 72 & .247 & .351 & & & \\
\hline 66 & .505 & .513 & 73 & .644 & .754 & & & \\
\hline 67 & .468 & .676 & 74 & .391 & .624 & & & \\
\hline 68 & .439 & .704 & 75 & .725 & .739 & & & \\
\hline 69 & .110 & .613 & 76 & .661 & .732 & & & \\
\hline 70 & .250 & .525 & 77 & .470 & .589 & & & \\
\hline
\end{tabular}

\section{Construct Validity}

The internal consistency indicators of the scale were calculated using the correlation coefficient between each scale item, and the total scale score and the domain score (Table 2).

It is evident from the previous table that the majority of the scale statements scored highly in their relevance to the overall score of the domain to which they belong and to the scale as a whole, and this indicates that the Creative Leadership scale has high consistency.

\section{Reliability of the scale}

To ensure the reliability of the scale, the study adopted two methods; the first was Cronbach's Alpha coefficient, whereas the second was the stability factor. It is clear from the results shown in table (3) that the scale has a good reliability score.
Table 3. Reliability coefficients of the creative leadership scale domains

\begin{tabular}{ccc}
\hline Domain & $\begin{array}{c}\text { Cronbach's } \\
\text { Alpha }\end{array}$ & $\begin{array}{c}\text { Stability } \\
\text { coefficient }\end{array}$ \\
\hline Vision & .737 & .339 \\
Planning & .732 & .462 \\
Social communication & .702 & .474 \\
Motivation & .805 & .703 \\
Team building & .802 & .600 \\
Public relations & .733 & .571 \\
Management & .710 & .485 \\
Communication & .766 & .561 \\
Conflict resolve & .841 & .673 \\
Decision making & .812 & .600 \\
Problem solving & .864 & .488 \\
\hline
\end{tabular}




\section{The Training Program}

Aim of the program

General Aim: The aim of this training program was to develop the creative leadership skills among the gifted students enrolled in the "Talent and Creativity Program" launched by International Pioneers Academy in Amman, through providing qualitative and effective opportunities to develop these skills, and conducting the necessary activities and tasks that ensure the autonomy of learning among students participating in the program.

\section{Specific Aims:}

1. Acquisition of a knowledge background about the creative leadership and problem solving skills.

2. Improving students' planning skills

3. Employing leadership skills in different situations.

4. Developing effective management skills

5. Tracking practical steps to make decisions.

6. Students' acquisition of communication skills

7. Students' mastering of problem solving skills

8. Training on creative thinking skills

9. Improving students' capacity to use research skills

10. Improving students' conflict resolving skills

\section{Philosophy of the program}

The contemporary world is witnessing a tremendous and rapid movement of change and development in all areas of life, and the leading human cadres have become the main pillar and backbone of the productive revolution to keep pace with these developments and absorb them in all institutions.

The delay in development in achieving the aspirations of the people can be referred to the lack of care in choosing the leadership cadres capable of developing societies and running the world. Therefore, caring for talented students is an investment process for human energies that represent an important sector of the human forces with their energies, preparations and capabilities for guidance and leadership, they are the ones that have the ability to open new horizons coordinated to overcome the problems and obstacles facing the progress and development of their societies.

Since leadership is one of the behavioral qualities of the gifted and one of their characteristics, gifted students have a great deal of leadership qualities compared to ordinary students. They are prepared and ready to take on leadership roles at early ages. In addition, creativity is one of the main elements of talent, and if his/her skills are available with the leadership skills of the gifted student, we should have foreseen the presence of creative leaders in all institutions, so these skills need upbringing, care and training.

\section{Content of the Training Program}

The training program consisted of three units, they were:
1. Unit one: Leaders and Leadership. This unit comprised of three sessions

- Session One: Leadership Way, which included theoretical knowledge about the concept of creative leadership and bibliography of selected known leaders.

- $\quad$ Session Two: Leadership Factory, which is a training session for the gifted students in the experimental group with a specialist in leadership.

- Session Three: My Model Role: In this session, the students met a youth team leader and discussed their goals, plans and leadership skills they have with the youth team leader.

2. Unit Two: Leadership rounds: This unit comprised of 15 sessions that were specialized in the investigated creative leadership skills in this program, which are: Vision, planning, motivation, social communication, public relations, team building, conflict resolving, decision making, management and problem solving. The 22 sessions were task-based sessions, as the students were given three tasks for each skill. The students were asked to perform these tasks based on their understanding of the creative leadership knowledge they acquired in unit one. Each skill had two sessions, the first is to perform the task, whereas the second was to present the achievement of the students and present it orally.

3. Unit Three: My Leadership Production. This unit comprised of two sessions where the students' received assessment and feedback about their tasks performed in unit two. In addition, a group discussion was performed to enrich the students' experiences and their knowledge about the performed tasks.

\section{Assessment Tools}

The present study adopted the following assessment tools that are compatible with the major aim of the training program:

1. Pre-assessment: The creative leadership skills scale was used before the introduction of the training program to the gifted students in the experimental group, in order to determine the level of the creative leadership skills they possess.

2. Formative Assessment: This assessment was represented by assessing the tasks given to the gifted students and the level of achievement.

3. Post-assessment: The creative leadership skills scale was used after the introduction of the training program to the gifted students in the experimental group, in order to determine the level of the creative leadership skills they possess.

\section{Validity of the Program}

To ensure the validity of the training program based on Betts autonomous learner model as a mean to develop the 
creative leadership skills, the program was sent to a group of 8 jury members who are specialized in education, psychology and leadership. The jury members were asked kindly to provide their comments and suggestions. The most significant suggestions were determining the time of the tasks given to the students and adding a specific title for each session.

\section{The Implementation Procedure of the Training Program}

Time: The program was implemented over four weeks, as each week had two sessions, except the last week that included one session. Therefore, the total was 19 sessions. The pre and post administration of the creative leadership scale was performed in two extra sessions at the beginning and the end of the training program.

Place: Young Leaders Hall in The International Pioneers Academy in Amman, Jordan.

\section{Statistical Processing}

Means, standard deviations, and paired samples t-test were used to compare the pre and post mean scores of the study groups (control and experimental groups). A significance level of 0.05 was used in this study.

\section{Results}

Detecting the differences between the mean scores of the post-assessment of the creative leadership skills among the gifted students in the study groups, and the effect size.

Independent samples t-test was used to detect the statistical differences between the mean scores of two independent samples and their standard deviation through finding the value of (t), to compare between the mean score and the standard deviation in the post-assessment scale for the study groups on the creative leadership scale, which are: vision, planning, social communication, motivation, team building, public relations, management, communication, conflict resolve, decision making, and problem solving. The results were as shown in table (4).

It is obvious from the results shown in table (4) that there were significant statistical differences in the post-assessment measurements of the study groups (control and experimental) in all creative leadership domains, as the $t$ value was statistically significant at a level of significance of $(\alpha \leq 0.05)$ in favor of the experimental group. These results indicated that the independent variable, which is the training program based on Betts autonomous learner model had a clear and significant effect in the superiority of the experimental group in the creative leadership skills, which are: vision, planning, social communication, motivation, team building, public relations, management, communication, conflict resolve, decision making, and problem solving. Therefore, the experimental group outperformed the control group in the post-assessment of the creative leadership skills scale.

The effect size of the training program based on Betts autonomous learner model was measured, and the percentage (the effect size X 100) was calculated. The results shown in table (5) show the effect size for each skill.

Through the calculated effect size shown in table (5) for the creative leadership skills, we conclude that the effect size percentage of the training program based on Betts autonomous learner model ranged between $57 \%$ and $85 \%$, which means that the effectiveness of the training program on the creative leadership skills was moderate to high. The skill of conflict resolving had the highest effect size, whereas the skill of vision had the lowest effect size. It is concluded as well that the training program had a good effect on developing the creative leadership skills (vision, planning, social communication, motivation, team building, public relations, management, communication, conflict resolve, decision making, and problem solving.) in favor of the experimental group. 
Table 4. Means and standard deviation scores for the gifted students scores in the control and experimental groups and t-values to test the differences between the mean scores

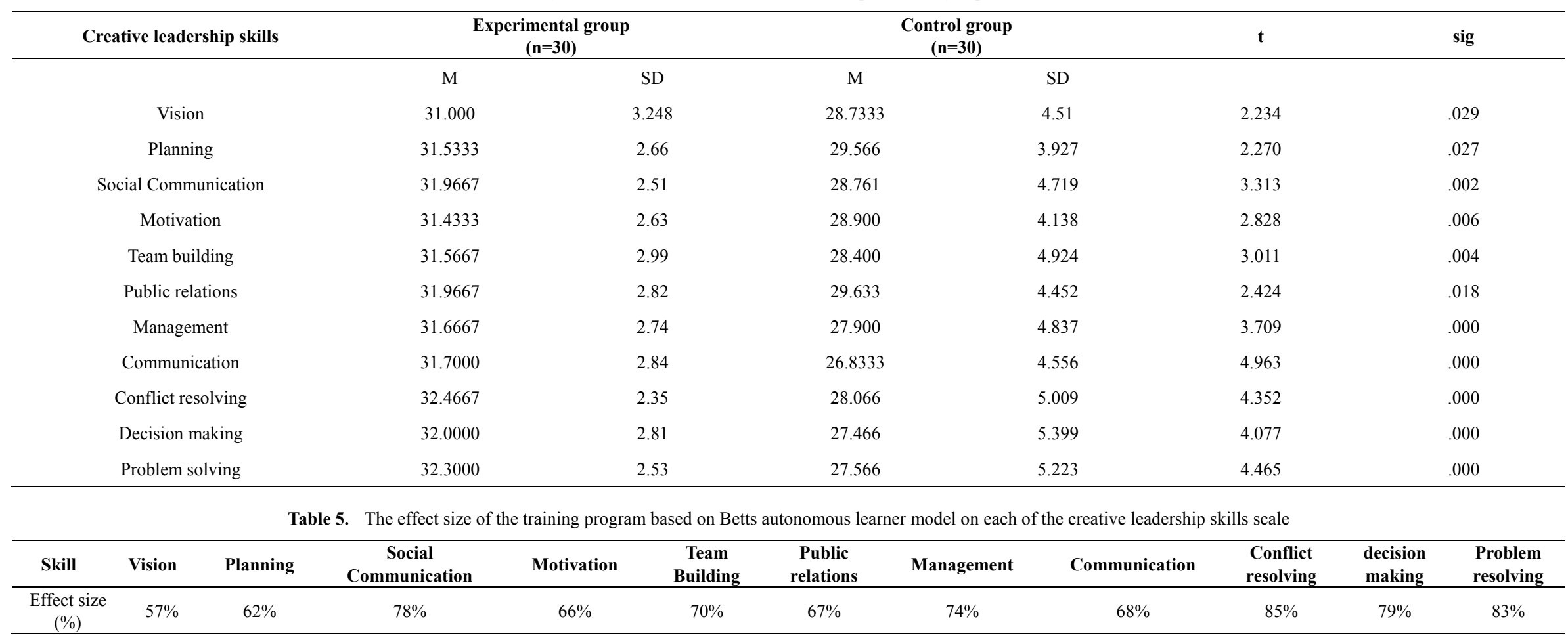


Table 6. Paired samples t-test for the pre and post-assessment mean scores of the experimental group on the creative leadership skills

\begin{tabular}{cccccccc}
\hline Creative leadership skills & \multicolumn{2}{c}{ Pre-Assessment } & \multicolumn{2}{c}{ Post-assessment } & df & t & sig \\
\hline M & SD & M & SD & & & \\
Vision & 29.6667 & 3.437 & 31.000 & 3.248 & 29 & 1.783 & .085 \\
Planning & 28.6667 & 3.294 & 31.5333 & 2.66 & 29 & 4.776 & .000 \\
Social Communication & 30.4000 & 2.685 & 31.9667 & 2.51 & 29 & 3.470 & .002 \\
Motivation & 29.9333 & 3.362 & 31.4333 & 2.63 & 29 & -3.398 & .002 \\
Team building & 29.4333 & 4.141 & 31.5667 & 2.99 & 29 & -3.164 & .004 \\
Public relations & 30.8333 & 3.322 & 31.9667 & 2.82 & 29 & -2.367 & .025 \\
Management & 29.4667 & 3.411 & 31.6667 & 2.74 & 29 & -4.131 & .000 \\
Communication & 29.5667 & 3.559 & 31.7000 & 2.84 & 29 & -3.256 & .003 \\
Conflict resolving & 30.1000 & 2.928 & 32.4667 & 2.35 & 29 & -3.933 & .000 \\
Decision making & 29.8000 & 4.046 & 32.0000 & 2.81 & 29 & -4.199 & .000 \\
Problem solving & 30.3667 & 3.863 & 32.3000 & 2.53 & 29 & -2.989 & .006 \\
\hline
\end{tabular}

Table 7. Paired samples t-test for the pre and post-assessment mean scores of the experimental group on the creative leadership skills

\begin{tabular}{ccccccccc}
\hline Creative leadership skills & \multicolumn{2}{c}{ Pre-Assessment } & \multicolumn{2}{c}{ Post-assessment } & df & t & sig \\
\hline & M & SD & M & SD & & & & \\
Vision & 29.30 & 4.549 & 28.7333 & 4.51 & 29 & .582 & .565 \\
Planning & 29.833 & 4.227 & 29.566 & 3.927 & 29 & .330 & .744 \\
Social Communication & 30.00 & 3.523 & 28.761 & 4.719 & 29 & 1.695 & .101 \\
Motivation & 29.6667 & 4.558 & 28.900 & 4.138 & 29 & .882 & .385 \\
Team building & 29.5667 & 4.091 & 28.400 & 4.924 & 29 & 1.243 & .224 \\
Public relations & 30.400 & 3.944 & 29.633 & 4.452 & 29 & .883 & .384 \\
Management & 29.500 & 4.150 & 27.900 & 4.837 & 29 & 1.729 & .094 \\
Communication & 29.800 & 3.898 & 26.8333 & 4.556 & 29 & 3.268 & .003 \\
Conflict resolving & 30.3667 & 3.995 & 28.066 & 5.009 & 29 & 2.294 & .029 \\
Decision making & 29.200 & 4.626 & 27.466 & 5.399 & 29 & 1.718 & .097 \\
Problem solving & 30.500 & 3.636 & 27.566 & 5.223 & 29 & 2.756 & .010 \\
\hline
\end{tabular}

Testing the significant differences between the pre and post-assessment mean scores of the gifted students in the experimental group for the creative leadership skills

Paired samples t-test was used to compare the pre and post-assessment mean scores of the experimental group. The results shown in table (6) indicate the $t$ values for the paired samples t-test.

It is obvious from the results in table (6) that there were significant statistical differences between the pre and post-assessment on all of the creative leadership skills, except for the vision skill, as the $t$ test value was statistically significant at level of significance of $(\alpha \leq 0.05)$, which indicated the effect of the training program based on Betts autonomous learner model on developing creative leadership and problem-solving skills among the participants in the experimental group after the completion of the interventional stage.
Testing the significant differences between the pre and post-assessment mean scores of the gifted students in the control group for the creative leadership skills

Paired samples t-test was used to compare the pre and post-assessment mean scores of the control group. The results shown in table (7) indicate the $t$ values for the paired samples t-test. The results showed that there were no significant statistical differences between the pre and post-assessment mean scores of the control group participants on the creative leadership skills scale as the $t$ values were non-significant at significance level of $(\alpha \leq 0.05)$, except for communication, conflict resolve, and problem solving skills.

\section{Discussion}

The present study aimed at investigating the effect of a training program based on Betts autonomous learner 
model on developing creative leadership and problem-solving skills of gifted students in Jordan. The results of the study showed that there was a significant improvement of the creative leadership skills among the participants who received the designed training program. The participants' planning, social communication, motivation, team building, public relations, management, communication, conflict resolving, decision making and problem solving skills were significantly enhanced due to the introduced training program. These results could be referred to that the content of the training program represented by the orientation, individual development, enrichment, seminars and the in-depth study had a powerful effect on the students' capabilities to acquire the above mentioned skills. The content of the program provided the students with sufficient knowledge about creativity and what is meant by being a gifted student. In addition, the activities included in the training program provided the participants in the experimental group with the opportunity to develop the cognitive, emotional, social, and physical skills. The training program focused on inter and intra personal development learning and organizational skills. The learners had the chance to work independently, which increased their sense of responsibility about their learning.

Using autonomous learning model, the students will become independent, self-directed and life-long learners. In autonomous learning, the students are allowed to perform intellectual process through which the execution of cognitive and metacognitive strategies, sequential, objective, and procedural activities. Learners were responsible for decisions concerned with their learning and the implementation of those decisions. They were participating metacognitively, motivationally and behaviorally in their own learning process.

The results of the study are consistent with the findings reported by Al-Shehri et al (2011), which indicated the effectiveness of enrichment program based on Betts autonomous learning model on developing the critical thinking skills among school students. In addition, these results are in line with the results reported by Al-Zoubi, and Bani Abdel Rahman (2011) that indicated the effectiveness of the enrichment programs based on Betts autonomous learning model in improving the management and problem solving skills among gifted students in Saudi Arabia.

\section{Conclusions}

The present study concluded that adopting a training program based on Betts autonomous learning model is an effective approach on developing the creative leadership and problem solving skills among the gifted students. This model allows the students to independently use metacognitive and behavioral approaches to take and implement decisions related to their learning situations. The present study recommends implementing the designed training program in the educational process of the gifted students in the gifted students' centers in Jordan, and providing a comprehensive educational package to activate the autonomous learning programs designed for developing the creative leadership skills among gifted students.

\section{REFERENCES}

[1] Barakat, M., Perceptions of educational leaders regarding contemporary reform initiatives in Egypt. Journal of Educational Administration and History, 2019. 51(4): p. 330-351.

[2] Pacini-Ketchabaw, V., S. Kind, and L.L. Kocher, Encounters with materials in early childhood education. 2016: Taylor \& Francis.

[3] McCoy, D.C., et al., Impacts of early childhood education on medium-and long-term educational outcomes. Educational Researcher, 2017. 46(8): p. 474-487.

[4] Betts, G., B. Kapushion, and R.J. Carey, The autonomous learner model: Supporting the development of problem finders, creative problem solvers, and producers of knowledge to successfully navigate the 21st Century, in Giftedness and Talent in the 21st Century. 2016, Brill Sense. p. 199-220.

[5] Betts, G.T., R.J. Carey, and B.M. Kapushion, Autonomous Learner Model Resource Book. 2016: ERIC.

[6] Pinto, R.K. and C. AC, Effect of Autonomous Learner Model on Self-Esteem of Secondary School Students with Different Levels of Achievement. Journal on School Educational Technology, 2018. 13(3): p. 27-36.

[7] Dobrotina, I.N. and E.L. Erokhina. Paradigm of the student-teacher relationship in the modern educational environment. in SHS Web of Conferences. 2016. EDP Sciences.

[8] Ogurlu, U. and M.N. Sevim, The opinions of gifted students about leadership training. Journal of Ethnic and Cultural Studies, 2017. 4(2): p. 41-52.

[9] Kashani-Vahid, L., et al., Can a creative interpersonal problem solving program improve creative thinking in gifted elementary students? Thinking skills and creativity, 2017. 24: p. 175-185.

[10] Lin, M.T.-Y., et al., A study on the effect of virtual reality $3 D$ exploratory education on students' creativity and leadership. EURASIA Journal of Mathematics, Science and Technology Education, 2017. 13(7): p. 3151-3161.

[11] Swanson, J.D., Drawing upon lessons learned: Effective curriculum and instruction for culturally and linguistically diverse gifted learners. Gifted Child Quarterly, 2016. 60(3): p. 172-191.

[12] Tam, R.K.-W., Nurturing gifted and talented students to become future leaders: The innovative curriculum for the 
gifted and/or talented at GT College in Hong Kong. Gifted Education International, 2017. 33(3): p. 248-256.

[13] Lee, S.-Y., et al., Gifted students' perceptions about leadership and leadership development. High Ability Studies, 2020: p. 1-41.

[14] Karagianni, D. and A. Jude Montgomery, Developing leadership skills among adolescents and young adults: a review of leadership programmes. International Journal of Adolescence and Youth, 2018. 23(1): p. 86-98.

[15] Al-Turief, M.A., E.A. Alzeghoul, and F.A. Aljasim, The Effectiveness of the Future Leadership Program in Developing Transformational Leadership Behavior among 7th Gifted Female Students in the Kingdom of Saudi Arabia. Humanities and Social Sciences Series, 2020. 33(6).

[16] Smyth, E. and J.A. Ross, Developing leadership skills of pre-adolescent gifted learners in small group settings.
Gifted Child Quarterly, 1999. 43(3): p. 204-211.

[17] Al-Mannai, S., Study the effect of the leadership skills program on leadership skills and creativity of outstanding students in schools in the Kingdom of Bahrain. Journal of Psychological studies, 2010. 20(4): p. 456-466.

[18] Worrell, F.C., et al., Gifted students. Annual review of psychology, 2019. 70: p. 551-576.

[19] Gandolfi, F. and S. Stone, Leadership, leadership styles, and servant leadership. Journal of Management Research, 2018. 18(4): p. 261-269.

[20] Keamy, R., Creative leadership? 'It's just the norm'. School Leadership \& Management, 2016. 36(2): p. 151-168.

[21] Zulaihah, S., R. Harida, and H. Setiawan. 3K: EASY KEYS TO DEVELOP AN AUTONOMOUS LEARNER. in INTERNATIONAL SEMINAR ON EDUCATION. 2020. 